\title{
Effect of medium pH on chemical selectivity of oxalic acid biosynthesis by Aspergillus niger W78C in submerged batch cultures with sucrose as a carbon source
}

\author{
Ewa Walaszczyk ${ }^{1} \mathbb{D} \cdot$ Waldemar Podgórski $^{1} \cdot$ Małgorzata Janczar-Smuga $^{2} \cdot$ Ewelina Dymarska $^{1,3}$
}

Received: 22 July 2017 / Accepted: 28 November 2017 / Published online: 5 December 2017

(c) The Author(s) 2017. This article is an open access publication

\begin{abstract}
The $\mathrm{pH}$ of the medium is the key environmental parameter of chemical selectivity of oxalic acid biosynthesis by Aspergillus niger. The activity of the enzyme oxaloacetate hydrolase, which is responsible for decomposition of oxaloacetate to oxalate and acetate inside the cell of the fungus, is highest at $\mathrm{pH}$ 6. In the present study, the influence of $\mathrm{pH}$ in the range of 3-7 on oxalic acid secretion by A. niger W78C from sucrose was investigated. The highest oxalic acid concentration, $64.3 \mathrm{~g} \mathrm{dm}^{-3}$, was reached in the medium with $\mathrm{pH} 6$. The chemical selectivity of the process was $58.6 \%$ because of the presence of citric and gluconic acids in the cultivation broth in the amount of 15.3 and $30.2 \mathrm{~g} \mathrm{dm}^{-3}$, respectively. Both an increase and a decrease of medium $\mathrm{pH}$ caused a decrease of oxalic acid concentration. The obtained results confirm that $\mathrm{pH} 6$ of the carbohydrate medium is appropriate for oxalic acid synthesis by A. niger, but the chemical selectivity of the process described in this paper was high in comparison to values reported previously in the literature.
\end{abstract}

Keywords Oxalic acid $\cdot$ Aspergillus niger $\cdot$ Biosynthesis $\cdot \mathrm{pH} \cdot$ Chemical selectivity

\section{Introduction}

Oxalic acid (ethanedioic acid, OA), the first in the homologous series of aliphatic dicarboxylic acids, is used in various industrial areas, such as metal surface treatment and textile manufacture and processing (Sawada and Murakami 2000). Although the greatest demand for it is in the pharmaceutical industry, the acid has been reported to be widely used in the chemical industry (Abraham et al. 2014; Kundu et al. 2015;

Ewa Walaszczyk

ewa.walaszczyk@ue.wroc.pl

1 Department of Biotechnology and Food Analysis, Institute of Chemistry and Food Technology, Faculty of Engineering and Economics, Wroclaw University of Economics, Komandorska 118-120, 53-345 Wrocław, Poland

2 Department of Animal Food Technology, Institute of Chemistry and Food Technology, Faculty of Engineering and Economics, Wroclaw University of Economics, Komandorska 118-120, 53-345 Wrocław, Poland

3 Department of Human Nutrition, Faculty of Health Sciences and Physical Education, The Witelon State University of Applied Sciences in Legnica, Sejmowa 5A, 59-220 Legnica, Poland
Lesmana and $\mathrm{Wu} 2014)$, in biohydrometallurgy (Qu et al. 2015; Vakilchap et al. 2016) and in environmental protection (Bahaloo-Horeh and Mousavi 2017; Bahaloo Horeh et al. 2016; Mi et al. 2015). Its wide applications emerge from its chemical properties to complex or bond metals to form metal complexes or salts in mostly insoluble compounds.

The metal oxalates-potassium, calcium, sodium, manganese or iron salts - are widely distributed in the plant kingdom. They play significant roles in heavy metal detoxification, calcium level regulation and defence against fungal or insect infections (Gadd et al. 2014; Sawada and Murakami 2000). Because of its wide presence in vegetable food products, oxalic acid may be used instead of strong inorganic acids such as sulphuric or nitric acid as anti-browning and preservation agents in fruit and vegetable storage (Cefola and Pace 2015; Li et al. 2016; RuízJiménez et al. 2014; Wang et al. 2016). There is social resistance to the use of chemically synthesised additives in the food industry, thus other natural ways of their production are being sought. Oxalic acid is biologically produced widely by various microorganisms, among which the filamentous fungus Aspergillus niger is recognised as the best producer (Musiał et al. 2006; Podgórski and Leśniak 2003; Strasser et al. 1994). The biosynthesis of oxalic acid in $A$. 
niger is possible exclusively by splitting of oxaloacetate formed directly from pyruvate to oxalate and acetate by the enzyme oxaloacetate hydrolase (OAH) [E.C. 3.7.1.1.] (Gadd et al. 2014; Kubicek et al. 1988; Pedersen et al. 2000a). The secretion of oxalic acid is a reaction to environmental changes: it is produced when the ambient $\mathrm{pH}$ is near neutral, and its role is to lower the $\mathrm{pH}$ quickly to prevent competing microorganisms from growing (Andersen et al. 2009; Poulsen et al. 2012). That is why the optimal activity of OAH is in the $\mathrm{pH}$ range of 5-8 (Pedersen et al. 2000b; Ruijter et al. 1999).

Sucrose was found to be the most suitable carbon source for oxalic acid biosynthesis by A. niger, but the large amount of gluconic and citric acids produced then by the fungus causing low chemical selectivity of the processes was indicated as the main disadvantage of using this substrate (Cameselle et al. 1998; Musial et al. 2005; Strasser et al. 1994; Walaszczyk et al. 2014, 2017). In the experiments described in this paper, both the oxalic acid concentration and the chemical selectivity of its biosynthesis are high in comparison to those reported earlier in the literature despite using sucrose as a sole carbon source. The paper also presents a detailed description of changes in concentration of secreted acids during cultivation of $A$. niger $\mathrm{W} 78 \mathrm{C}$ at different $\mathrm{pH}$ values.

The aim of the study was to determine the influence of medium $\mathrm{pH}$ on chemical selectivity of the biosynthesis of oxalic acid from sucrose by A. niger $\mathrm{W} 78 \mathrm{C}$ in submerged batch cultures.

\section{Experimental}

\section{Materials and medium preparation}

The experiments were carried out with A. niger W78C strain from the collection of the Department of Biotechnology and Food Analysis, Wroclaw University of Economics (Poland), selected in previous research (Walaszczyk et al. 2015) as the strain with the highest oxalic acid production selectivity from sucrose.

The only carbon and energy source for the microorganism was sucrose in the form of white sugar. The synthetic medium, used in previous experiments (Walaszczyk et al. 2014, 2017), consisted (per $1 \mathrm{dm}^{-3}$ ) of: sucrose $125 \mathrm{~g}$, $\mathrm{NH}_{4} \mathrm{NO}_{3} 1.89 \mathrm{~g}, \mathrm{KH}_{2} \mathrm{PO}_{4} 0.32 \mathrm{~g}, \mathrm{MgSO}_{4} \cdot 7 \mathrm{H}_{2} \mathrm{O} 0.64 \mathrm{~g}$, $\mathrm{ZnSO}_{4} \cdot 7 \mathrm{H}_{2} \mathrm{O} 0.97 \mathrm{mg}, \mathrm{CuSO}_{4} \cdot 5 \mathrm{H}_{2} \mathrm{O} 0.86 \mathrm{mg}, \mathrm{FeSO}_{4} \cdot 7 \mathrm{H}_{2} \mathrm{O}$ $1.64 \mathrm{mg}, \mathrm{MnSO}_{4} \cdot \mathrm{H}_{2} \mathrm{O} 1.02 \mathrm{mg}$, and distilled water. After sterilization, the medium was inoculated with spores of A. niger in the amount of about $3 \times 10^{5}$ per $1 \mathrm{~cm}^{3}$ of the medium.

\section{Culture conditions}

The experiments were carried out for $7-12$ days at $30{ }^{\circ} \mathrm{C}$ in a stirred tank reactor, Biostat A (Sartorius AG, Germany), with the working volume of $5 \mathrm{dm}^{3}$ filled with $4 \mathrm{dm}^{3}$ of the medium. The aeration and agitation were fixed at $6 \mathrm{dm}^{3} \mathrm{dm}^{-3} \mathrm{~h}^{-1}$ and $600 \mathrm{~min}^{-1}$, respectively. The $\mathrm{pH}$ was adjusted to a required level $(3,4,5,6$ or 7$)$ before sterilisation and regulated automatically by the addition of $10 \mathrm{M}$ $\mathrm{KOH}$ from the beginning of secretion of acids. The exact moment in each experiment was determined based on the courses of the curves of oxygen uptake and carbon dioxide output. The secretion of the acids started when the volumetric oxygen uptake rate exceeded the volumetric carbon dioxide evolution rate. It took place between 44 and $50 \mathrm{~h}$ of the process. The end of the process was set by the lack of increase of total acidity of the medium measured titrimetrically with $0.1 \mathrm{M} \mathrm{NaOH}$ in the presence of phenolphthalein.

\section{Analytical methods}

The samples of the culture broth were taken for analysis once daily in the amount of $25 \mathrm{~cm}^{3}$. The concentrations of organic acids were measured by HPLC using a Rezex ROA Organic Acid column (Phenomenex, USA) coupled to a UV detector at $210 \mathrm{~nm}$ and an RI detector (Perkin Elmer, USA). The column was eluted with $0.0025 \mathrm{M} \mathrm{H}_{2} \mathrm{SO}_{4}$ at room tem-

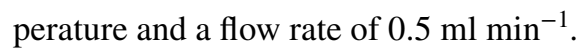

The statistical analysis of results was done with MS Excel 2013 and Statistica 12.0 (StatSoft, Inc., USA). Results were considered statistically significant at a level of $p \leq 0.05$.

\section{Results and discussion}

Aspergillus niger cultivated in medium containing carbohydrates produces mostly three organic acids-citric, oxalic and gluconic - and the medium $\mathrm{pH}$ is one of the most significant factors influencing this process (Papagianni 2007). The strong oxalic acid is synthesised when the environmental $\mathrm{pH}$ is slightly acidic or neutral to lower the $\mathrm{pH}$ in the shortest possible time to prevent the growth of competing microorganisms, mostly bacteria. The weaker citric acid with its buffering properties is secreted when the ambient $\mathrm{pH}$ is low, to maintain it and prevent it from rising. Gluconic acid production is optimal at pH 5.5, and it is not aimed at acidifying the medium but at storing all the glucose as a compound unavailable to competing microorganisms. The created gluconate is later reused by $A$. niger as a carbon source to produce other acids (Andersen et al. 2009; Poulsen et al. 2012). 
In the present study, the medium $\mathrm{pH}$ of $3,4,5,6$ and 7 was examined. The courses of oxalic (a), citric (b) and gluconic (c) acid concentrations obtained in medium with different $\mathrm{pH}$ values are presented in Fig. 1. Oxalic acid was detected in all medium variants from the third day $(72 \mathrm{~h})$ of the process and its amount grew rapidly during the next few days. The highest concentration, $64.3 \mathrm{~g} \mathrm{dm}^{-3}$, was reached at $240 \mathrm{~h}$ at $\mathrm{pH} 6$. Both the increase and the decrease of medium $\mathrm{pH}$ caused the decrease of oxalic acid concentration (Fig. 1a). These findings are in accordance with the results described by other authors who investigated the influence of $\mathrm{pH}$ on oxalic acid production in media with glucose or lactose as the carbon source (Bohlmann et al. 1998; Kubicek et al. 1988; Ruijter et al. 1999). They indicated that the most suitable medium $\mathrm{pH}$ for this process is 6 , but the amounts of product they obtained were low, between 8.0 and $21.3 \mathrm{~g} \mathrm{dm}^{-3}$. When sucrose was a carbon source and the medium $\mathrm{pH}$ was 6 , the concentration of oxalic acid reported in the literature was higher, between 33.8 and $64.2 \mathrm{~g} \mathrm{dm}^{-3}$ (Cameselle et al. 1998; Foryś and Podgórski 2004; Podgórski and Leśniak 2003; Strasser et al. 1994; Walaszczyk et al. 2015) or even $70.8 \mathrm{~g} \mathrm{dm}^{-3}$ (Walaszczyk et al. 2017), depending on medium composition and culture conditions.

In all the experiments, apart from oxalic acid, A. niger secreted accompanying acids: either only citric acid $(\mathrm{pH} 3)$ or citric and gluconic acids ( $\mathrm{pH} \mathrm{4,5,6,7)} \mathrm{(Fig.} \mathrm{1b,} \mathrm{c).} \mathrm{Citric}$ acid was detected in small amounts $\left(0.2-1.7 \mathrm{~g} \mathrm{dm}^{-3}\right)$ on the second day of cultivation $(48 \mathrm{~h})$. As expected (Papagianni 2007), the lower the $\mathrm{pH}$ of the medium was, the greater was the amount of citric acid produced and the later was the maximum concentration reached; the highest amount of this metabolite, $61.6 \mathrm{~g} \mathrm{dm}^{-3}$, was detected at $\mathrm{pH} 3$ at the 264th hour of the process (Fig. 1b). The opposite relation was found in the case of gluconic acid. This acid was present in high amounts in media with higher $\mathrm{pH}$, i.e., 5, 6 and 7 (Fig. 1c). With increasing medium $\mathrm{pH}$, its production began earlier and grew faster, and a higher concentration was reached; the highest amount of gluconic acid, $65.7 \mathrm{~g} \mathrm{dm}^{-3}$, was found at $\mathrm{pH} 7$ at the 120th hour of cultivation. At the same time of the process, the highest concentrations of this by-product, 60.3 and $60.0 \mathrm{~g} \mathrm{dm}^{-3}$, were detected in media with $\mathrm{pH}$ levels of 5 and 6 , respectively. In the medium variant with the lowest tested $\mathrm{pH}$, i.e., 3, there was no gluconic acid present, and at $\mathrm{pH} 4$, a small amount of the acid was found solely at the 48th hour. Probably either the enzyme glucose oxidase [E.C. 1.1.3.4.] involved in glucose transformation to gluconic acid was not active at lower $\mathrm{pH}$ values [its maximum activity is reported to be at $\mathrm{pH} 5.5$ (Andersen et al. 2009; Papagianni 2007)] or the entire amount of carbon source was used to produce citric and oxalic acids (Fig. 1a, b).

In most of the experiment variants (all beside the medium with $\mathrm{pH} 3$ ) the concentration of accompanying citric and
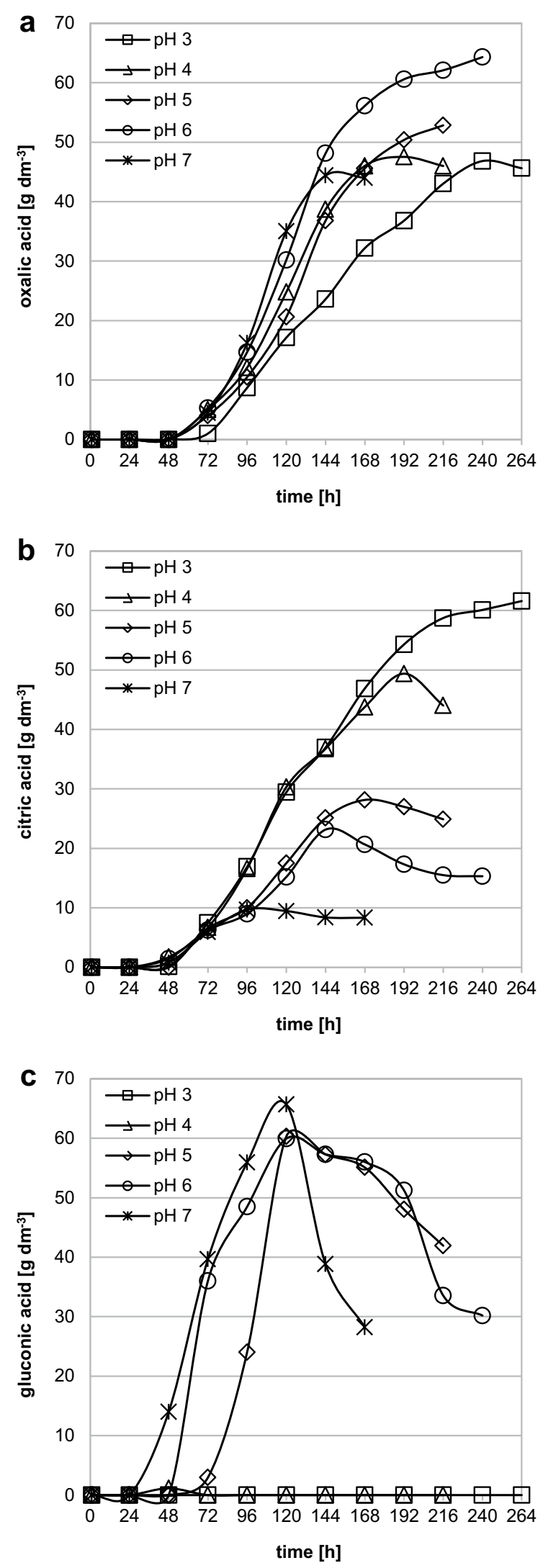

Fig. 1 The courses of oxalic (a), citric (b) and gluconic (c) acids concentration during cultivation of $A$. niger W78C in defined medium with sucrose at different $\mathrm{pH}$ values 
gluconic acids decreased after reaching the maximum (Fig. 1b, c). The acids were probably reused by A. niger as carbon sources to produce oxalic acid because the $\mathrm{pH}$ was constantly automatically regulated and this acid's role is to lower the $\mathrm{pH}$ quickly. The same cultivation courses and conclusions were reported by other authors (Cameselle et al. 1998; Musiał et al. 2005; Poulsen et al. 2012; Strasser et al. 1994; Walaszczyk et al. 2014, 2017). It is worth mentioning that the final concentration of gluconic acid in all experiments presented in this paper was lower than that of oxalic acid, in contrast to some of the other results of oxalic acid biosynthesis from sucrose (Cameselle et al. 1998; Musiał et al. 2005; Strasser et al. 1994).

Because A. niger cultivated in sucrose defined media beside oxalic acid also secretes citric and gluconic acids, as described earlier, the selectivity of oxalic acid biosynthesis is one of the most important parameters for evaluation of the results. The courses of chemical selectivity expressed as the relation of the amount of oxalic acid to the amount of all the acids secreted by A. niger, at different medium $\mathrm{pH}$ values, are shown in Fig. 2. The chemical selectivity of most processes grew constantly from the beginning of oxalic acid presence in the cultivation broth. The exception was the cultivation at $\mathrm{pH} 5$ when at $96 \mathrm{~h}$ and at $120 \mathrm{~h}$ the gluconic acid concentration grew significantly in relation to its value at $72 \mathrm{~h}$ (Fig. 1c), so the chemical selectivity dropped. The maximum value of chemical selectivity, 58.6\%, was reached at $240 \mathrm{~h}$ at $\mathrm{pH} 6$ (Fig. 2). Such chemical selectivity of oxalic acid biosynthesis by $A$. niger from sucrose is higher than that described by other authors: Strasser et al. (1994) reported selectivity of $38.7 \%$, Cameselle et al. (1998) $40.8 \%$ and Musiał et al. (2005) only $27.1 \%$. All these authors detected amounts of gluconic acid higher than oxalic acid in their cultivation liquids and indicated that as the main disadvantage of using sucrose as a carbon source for this process. Only in our own previous research (Walaszczyk et al. 2015,

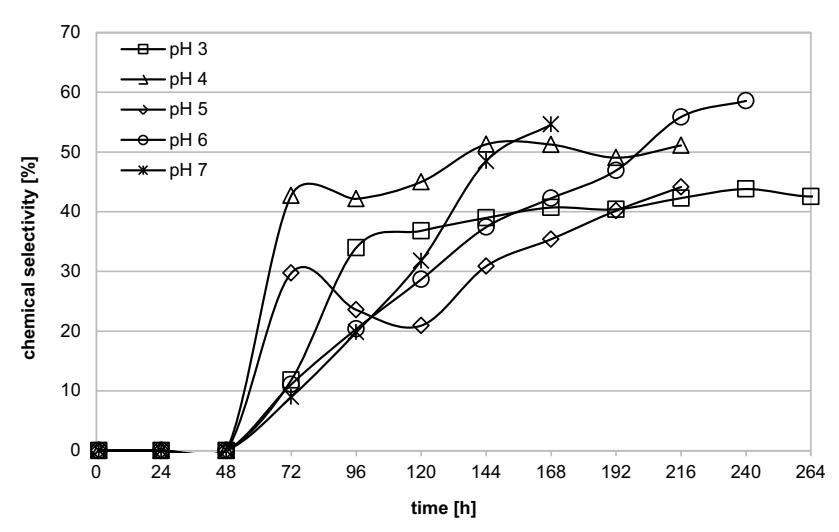

Fig. 2 The course of chemical selectivity of oxalic acid biosynthesis by $A$. niger $\mathrm{W} 78 \mathrm{C}$ cultivated in defined medium with sucrose at different $\mathrm{pH}$ values
2017) was the chemical selectivity of conducted processes of oxalic acid bioproduction from sucrose higher, $69.8-72.1 \%$.

\section{Conclusions}

The presented results show that medium $\mathrm{pH}$ is an important factor influencing secretion of organic acids by A. niger W78C in submerged batch cultures with sucrose as the carbon source. The study findings confirm that the most suitable medium $\mathrm{pH}$ for oxalic acid biosynthesis from sucrose is 6. Despite the large amounts of accompanying acids, mostly gluconic, both the final concentration of the product and the chemical selectivity of the process were high. Further research will be conducted to eliminate co-production of unwanted by-products, so the chemical selectivity of oxalic acid biosynthesis could significantly rise.

Open Access This article is distributed under the terms of the Creative Commons Attribution 4.0 International License (http://creativecommons.org/licenses/by/4.0/), which permits unrestricted use, distribution, and reproduction in any medium, provided you give appropriate credit to the original author(s) and the source, provide a link to the Creative Commons license, and indicate if changes were made.

\section{References}

Abraham F, Arab-Chapelet B, Rivenet M, Tamain C, Grandjean S (2014) Actinide oxalates, solid state structures and applications. Coordin Chem Rev 266-267(1):28-68. https://doi.org/10.1016/j. ccr.2013.08.036

Andersen MR, Lehmann L, Nielsen J (2009) Systemic analysis of the response of Aspergillus niger to ambient $\mathrm{pH}$. Genome Biol 10(5):R47. https://doi.org/10.1186/gb-2009-10-5-r47

Bahaloo Horeh N, Mousavi SM, Shojaosadati SA (2016) Bioleaching of valuable metals from spent lithium-ion mobile phone batteries using Aspergillus niger. J Power Sources 320:257-266. https:// doi.org/10.1016/j.jpowsour.2016.04.104

Bahaloo-Horeh N, Mousavi SM (2017) Enhanced recovery of valuable metals from spent lithium-ion batteries through optimization of organic acids produced by Aspergillus niger. Wastes Manag 60:666-679. https://doi.org/10.1016/j.wasman.2016.10.034

Bohlmann JT, Cameselle C, Nunez MJ, Lema JM (1998) Oxalic acid production by Aspergillus niger. Part II: optimisation of fermentation with milk whey as carbon source. Bioprocess Eng 19(5):337342. https://doi.org/10.1007/PL00009022

Cameselle C, Bohlmann JT, Núñez MJ, Lema JM (1998) Oxalic acid production by Aspergillus niger. Part I: influence of sucrose and milk whey as carbon source. Bioprocess Eng 19:247-252. https:// doi.org/10.1007/PL00009017

Cefola M, Pace B (2015) Application of oxalic acid to preserve the overall quality of rocket and baby spinach leaves during storage. J Food Process Preserv 39(6):2523-2532. https://doi.org/10.1111/ jfpp. 12502

Foryś E, Podgórski W (2004) Application of replicated 2^3 full factorial central composite circumscribed design of experiment (CCC DOE) for optimization of oxalate biosynthesis by Aspergillus niger W78C. Acta Sci Pol Biotechnol 3(1-2):43-53 
Gadd GM, Bahri-Esfahani J, Li Q, Rhee YJ, Wei Z, Fomina M, Liang X (2014) Oxalate production by fungi: significance in geomycology, biodeterioration and bioremediation. Fungal Biol Rev 28(2-3):36-55. https://doi.org/10.1016/j.fbr.2014.05.001

Kubicek CP, Schreferl-Kunar G, Wöhrer W, Röhr M (1988) Evidence for a cytoplasmic pathway of oxalate biosynthesis in Aspergillus niger. Appl Environ Microbiol 54(3):633-637

Kundu C, Lee HJ, Lee JW (2015) Enhanced bioethanol production from yellow poplar by deacetylation and oxalic acid pretreatment without detoxification. Bioresour Technol 178:28-35. https://doi. org/10.1016/j.biortech.2014.08.082

Lesmana D, Wu HS (2014) Modified oxalic acid co-precipitation method for preparing $\mathrm{Cu} / \mathrm{ZnO} / \mathrm{Al}_{2} \mathrm{O}_{3} / \mathrm{Cr}_{2} \mathrm{O}_{3} / \mathrm{CeO}_{2}$ catalysts for the OR (oxidative reforming) of $\mathrm{M}$ (methanol) to produce $\mathrm{H}_{2}$ (hydrogen) gas. Energy 69:769-777. https://doi.org/10.1016/j. energy.2014.03.073

Li P, Yin F, Song L, Zheng X (2016) Alleviation of chilling injury in tomato fruit by exogenous application of oxalic acid. Food Chem 202:125-132. https://doi.org/10.1016/j.foodchem.2016.01.142

Mi FL, Wu SJ, Lin FM (2015) Adsorption of copper(II) ions by a chitosan-oxalate complex biosorbent. Int J Biol Macromol 72:136144. https://doi.org/10.1016/j.ijbiomac.2014.08.006

Musiał I, Rymowicz W, Lenart D (2005) The use of post-refinary fatty acids for oxalic acid production by Aspergillus niger at low $\mathrm{pH}$ (in Polish). Biotechnologia 2(2):37-45

Musiał I, Rymowicz W, Witkowska D (2006) Effect of Span 20 concentration on oxalic acid production from post-refining fatty acids by Aspergillus niger XP. Chem Pap 60(5):388-390. https://doi. org/10.2478/S11696-006-0070-4

Papagianni M (2007) Advances in citric acid fermentation by Aspergillus niger: biochemical aspects, membrane transport and modeling. Biotechnol Adv 25:244-263. https://doi.org/10.1016/j. biotechadv.2007.01.002

Pedersen H, Christensen B, Hjort C, Nielsen J (2000a) Construction and characterization of an oxalic acid nonproducing strain of Aspergillus niger. Metab Eng 2(1):34-41. https://doi.org/10.1006/ mben.1999.0136

Pedersen H, Hjort C, Nielsen J (2000b) Cloning and characterization of oah, the gene encoding oxaloacetate hydrolase in Aspergillus niger. Mol Gen Genet 263(2):281-286. https://doi.org/10.1007/ s004380051169

Podgórski W, Leśniak W (2003) Biochemical method of oxalic acid production from beet molasses. Chem Pap 57(6):408-412
Poulsen L, Andersen MR, Lantz AE, Thykaer J (2012) Identification of a transcription factor controlling $\mathrm{pH}$-dependent organic acid in Aspergillus niger. PLoS One 7(12):e50596. https://doi. org/10.1371/journal.pone.0050596

Qu Y, Li H, Tian W, Wang X, Wang X, Jia X, Shi B, Song G, Tang Y (2015) Leaching of valuable metals from red mud via batch and continuous processes by using fungi. Miner Eng 81:1-4. https:// doi.org/10.1016/j.mineng.2015.07.022

Ruijter GJG, van de Vondervoort PJI, Visser J (1999) Oxalic acid production by Aspergillus niger: an oxalate-non-producing mutant produces citric acid at $\mathrm{pH} 5$ and in the presence of manganese. Microbiology 145:2569-2576. https://doi.org/10.1007/ s004490050515

Ruíz-Jiménez JM, Zapata PJ, Serrano M, Valero D, Martínez-Romero D, Castillo S, Guillén F (2014) Effect of oxalic acid on quality attributes of artichokes stored at ambient temperature. Postharvest Biol Technol 95:60-63. https://doi.org/10.1016/j. postharvbio.2014.03.015

Sawada H, Murakami T (2000) Oxalic acid. In: Seidel A (ed) KirkOthmer encyclopedia of chemical technology. Wiley, New York. https://doi.org/10.1002/0471238961.1524011219012301.a01

Strasser H, Burgstaller W, Schinner F (1994) High-yield production of oxalic acid for metal leaching processes by Aspergillus niger. FEMS Microbiol Lett 119:365-370

Vakilchap F, Mousavi SM, Shojaosadati SA (2016) Role of Aspergillus niger in recovery enhancement of valuable metals from produced red mud in Bayer process. Bioresour Technol 218:991-998. https://doi.org/10.1016/j.biortech.2016.07.059

Walaszczyk E, Dawidowicz K, Gąsiorek E, Podgórski W (2014) Influence of glucose concentration on oxalic acid synthesis by Aspergillus niger (in Polish). Acta Sci Pol Biotechnol 13(4):19-28

Walaszczyk E, Podgórski W, Gąsiorek E (2015) Aspergillus niger strain selection for oxalic acid biosynthesis from sucrose (in Polish). Res Pap Wroclaw Univ Econ 411:133-139. https://doi.org/10.15611/ pn.2015.411.12

Walaszczyk E, Gąsiorek E, Podgórski W (2017) Effect of sucrose concentration on oxalic acid biosynthesis by Aspergillus niger. Zeszyty Problemowe Postępów Nauk Rolniczych 588(129):138. https://doi.org/10.22630/ZPPNR.2017.588.12

Wang Z, Cao J, Jiang W (2016) Changes in sugar metabolism caused by exogenous oxalic acid related to chilling tolerance of apricot fruit. Postharvest Biol Technol 114:10-16. https://doi.org/10.1016/j. postharvbio.2015.11.015 